Article

\title{
The Transition to Parenthood in the French and German Speaking Parts of Switzerland
}

\author{
Regula Zimmermann ${ }^{1, *}$ and Jean-Marie Le Goff ${ }^{2}$ \\ ${ }^{1}$ Department of Social Sciences, University of Basel, 4051 Basel, Switzerland; E-Mail: regula.zimmermann@unibas.ch \\ 2 Institute of Social Sciences, Université de Lausanne, 1015 Lausanne, Switzerland; E-Mail: jean-marie.legoff@unil.ch \\ * Corresponding author
}

Submitted: 14 March 2020 | Accepted: 3 June 2020 | Published: 9 October 2020

\begin{abstract}
After the first transition to parenthood, most couples adopt a gendered labor division, where mothers become main caregivers and fathers breadwinners of the family. By comparing two distinct language regions within one country, the present article explores how parents' gendered labor division comes into existence and what role gendered culture and social policy play. The analysis draws on in-depth interviews with 23 German speaking and 73 French speaking participants from Switzerland. The results reveal that French speaking women and men presume an egalitarian labor division as parents. In German speaking regions, however, participants anticipate that mothers will become the main caregivers and fathers the breadwinners. It is shown that the labor market structure, which is in line with the male breadwinner norm, contributes to men's full-time employment, whereas mothers' labor market insertion is influenced by the acceptance of non-parental childcare and to a lesser extent by the offer of childcare facilities. Further, mothers experience more time conflicts than fathers, and the less mothers' paid work is accepted, the more they suffer from feelings of guilt when being employed.
\end{abstract}

\section{Keywords}

family policy; gender inequality; labor division; parenthood; Switzerland

\section{Issue}

This article is part of the issue "Division of Labour within Families, Work-Life Conflict and Family Policy" edited by Michael Ochsner (FORS Lausanne, Switzerland), Ivett Szalma (Centre for Social Sciences, Hungarian Academy of Sciences Centre of Excellence, Hungary/Corvinus University of Budapest, Hungary) and Judit Takács (Centre for Social Sciences, Hungarian Academy of Sciences Centre of Excellence, Hungary/KWI Essen, Germany).

(C) 2020 by the authors; licensee Cogitatio (Lisbon, Portugal). This article is licensed under a Creative Commons Attribution 4.0 International License (CC BY).

\section{Introduction}

The transition to parenthood is a turning point in the life course (Rönkä, Oravala, \& Pulkkinen, 2003). Parents' new roles as caregivers affect various domains, such as professional life (Gatrell, 2005), income (Misra, Budig, \& Boeckmann, 2011), life satisfaction (Carmichael \& Ercolani, 2016), and priorities (Grunow, 2019). Research shows that how parents experience this transition and which labor division they opt for is shaped by gender culture, as well as welfare state policies (Grunow \& Evertsson, 2016, 2019; Pfau-Effinger, 2005).

The present article proposes a comparison of how women and men anticipate and experience their first transition to parenthood in the French and German speaking regions of Switzerland. The French and German regions of Switzerland are described as "bounded communities" (Geser, 2003, p. 2), which differ in their values and discourses. This is especially the case in the domain of reconciling family and working life, in which ideals vary between the language regions (Armingeon, Bertozzi, \& Bonoli, 2004; Bühler, 2002). French speakers are more favorable to government support for families, as voting results show (FCh, 2004, 2013), and are less oriented towards a male breadwinner model than German speakers (Bühler, 2002). On the other hand, there is some commonality in family welfare policies between the regions, for example, in the labor market 
policy, but also some variation, for example, in the offered childcare services (Armingeon et al., 2004). In the present study, we are interested in taking into consideration the heterogeneity of gender culture in the context of a decentralized country. Our analysis is distinct from more common international comparisons which contrast differences between nation states, and mostly emphasize the role of policy, whereas culture is only marginally discussed (Pfau-Effinger, 2005). By using a qualitative approach, we analyze how culture and policy interact, thereby contributing to the understanding of how women's and men's decisions on how to reconcile paid work and care work are shaped, and which conflicts between the two they experience, during the first transition to parenthood.

In the first section of the article, we review literature on how culture and policy shape parents' labor division. Subsequently, we describe the specific context of Switzerland. This is followed by our own analysis which is drawn from the 'Anticipated Parenthood and Employment' study (AP; Maihofer, 2018), including 23 indepth interviews with German speaking and 11 French speaking individuals, as well as from the qualitative longitudinal data of the 'Becoming Parents' (BP) study (31 couples, among which partners were individually interviewed from French speaking Switzerland; see Le Goff \& Levy, 2011). The data include interviews with participants who anticipate or have already experienced their first transition to parenthood, allowing us to investigate how parents' gendered labor division comes into existence.

\section{Gendered Culture, Welfare Policy and Couples' Labor Division}

Over the last decades in OECD-countries, women's educational attainment has risen and the share of women in heterosexual relationships who have the same or more resources than their partners has increased (Vitali \& Mendola, 2014). Despite women's educational and professional achievements, after the transition to parenthood, most heterosexual couples opt for a gendered labor division. Mothers shoulder the majority of care work, and often reduce investment in their careers, whereas fathers remain focused on paid work (Kühhirt, 2011; Schober, 2011).

Gendered culture can be defined as "values, models and belief systems which relate to the gendered relationship of the family to employment and childcare" (Pfau-Effinger, 2012, p. 533). It includes widespread societal values and norms about what parents' labor division ideally looks like. It also shapes what is considered 'good' mothering and 'good' fathering and the most suitable form of care for the child. Gendered culture legitimizes inequalities and thus helps to explain the gendered labor division among parents (Pfau-Effinger, 2012). 'Intensive mothering,' a term coined by Hays (1996), describes a cultural position that promotes the essentialist view that women are better caregivers than men, and that moth- ers should devote vast amounts of time, and emotional as well as financial resources to child rearing. This notion of giving care conflicts with individualistic ideals inherent to professional life, which emphasize independence and self-reliance for career success. Many studies have confirmed that such expectations exert pressure on mothers, and thus influences their work and care priorities (Bielby, 1992; Johnston \& Swanson, 2006; Miller, 2005). However, fatherhood has changed over the last decades (Johansson \& Andreasson, 2017, p. 17). The 'ideal' father is no longer solely a breadwinner but is also 'involved' and 'emotionally engaged' in childrearing from infancy (Miller, 2011, p. 7 ). In practice, however, fathers typically arrange their care activities around their job obligations (McGill, 2014; Miller, 2011).

Moreover, welfare policies narrow parents' options for labor division (Bühlmann, Elcheroth, \& Tettamanti, 2010; Saraceno \& Keck, 2011). Cross-national comparisons reveal that mothers' employment rates and working hours are higher in contexts that provide childcare for young children. Furthermore, mothers' insertion in the labor market is linked to parental leave policies: moderate leave lengths (40-90 weeks) are positively related to labor market insertion, whereas shorter, but also more extended leaves are associated with a lower attachment to the labor force (Misra et al., 2011; Pettit \& Hook, 2005). Some countries have also created policies promoting fathers' caregiving, by offering them paid non-transferable leaves. These paternity leaves are associated with a higher investment of fathers in childcare, even beyond the leave time (O'Brien, 2009). Research has shown that policy not only has a direct impact on parents' labor division, but that it also influences gendered culture. As an example, the provision of childcare facilities acts as a cultural anchor, increasing acceptance of working mothers (see Grunow \& Evertsson, 2016, on European countries). In other respects, the extension of maternal leave entitlements reduces mothers' commitment to paid work (see Gangl \& Ziefle, 2015, on Germany). However, culture does not automatically follow policy. Policy must match the cultural values of at least some groups in society, otherwise it remains inefficient (Grunow \& Evertsson, 2016). Examples are Italy, where fathers do not take leave time despite financial compensation, because it collides with the cultural notion that mothers should be primary caregivers (Bertolini, Musumeci, Naldini, \& Torrioni, 2019) and South Korea, where mothers do not take advantage of $100 \%$ paid maternity leave, because it conflicts with cultural norms demanding deference to the employer and individual sacrifice (Lee, 2015). Overall, policy and gender culture limit the leeway for decision making for couples during the transition to parenthood, and the disparity between them makes it even more difficult for parents-to-be to plan their labor division. However, as gender culture and policy interact, and both vary between contexts, their relative effects are difficult to disentangle and remain contested (Grunow \& Evertsson, 2016, 2019; Pfau-Effinger, 2012). 


\section{The Respective Contexts of Work-Family Conciliation in the French and German Speaking Parts of Switzerland}

Switzerland is a mosaic combining different religious denominations, languages and lifestyles (Geser, 2003). Adapted to differences between regions, the country has a federalist structure. Cantons and sometimes municipalities retain important roles in driving family policy. Furthermore, based on direct democracy, Swiss citizens directly decide on a broad range of policies (Armingeon et al., 2004). The present study homes in on a comparison of the two major language regions: The German speaking and French speaking regions which represent $63 \%$ and $23 \%$ of the population, respectively.

In both language regions, mothers' work force participation increased during the second half of the 20th century, and labor division transformed from 'male breadwinner' into a 'one and a half'-earner-model, with fathers working full-time and mothers working part-time. Simultaneously, a shift in values can be observed in which the mother is not solely responsible for care work: The father should also take an active role in the children's upbringing (Baumgarten, Burri, \& Maihofer, 2017). Despite these changes, parents' labor division remains highly gendered. Fathers' labor force participation rate is high (97\%) and nine out of ten work full-time, which usually corresponds to $41.5 \mathrm{~h} /$ week. Mothers' insertion in the labor market varies between the language regions: After the birth of the first child, $67 \%$ of German speaking mothers and $75 \%$ of French speaking mothers remain in the labor force. $80 \%$ of mothers work part-time, despite this being linked to downward mobility (FSO, 2016; Strub, 2003). After the first transition to parenthood, French speaking mothers work on average 3.5 days/week, and German speaking mothers 2.5 days/week (FSO, 14 November 2019, personal communication). In both language regions, mothers shoulder the vast majority of unpaid work (FSO, 2013).

Switzerland's family policy is based on subsidiarity and non-intervention in the area of family. The existing social insurance schemes are largely designed to compensate for the loss of breadwinner income, and few policies support reconciliation of family and paid work (Ballestri \& Bonoli, 2003). The limited social policy is sometimes linked to direct democracy as voters tend to oppose social policies to avoid tax increases (Armingeon et al., 2004). However, national polls reveal differences between the language regions. French speakers are more open to state support for family than German speakers, as two recent votes about family policy have shown. In 2004, after four rejections, a paid maternity leave of 14 weeks was accepted, but acceptance rates were clearly higher in the French speaking parts of the country than in the German speaking parts (FCh, 2004). In 2013, an article that demanded more state support to reconcile family and paid work and the increase of subsidized childcare infrastructure was rejected by a majority of the German speaking regions, even though in French speaking regions it was accepted (FCh, 2013). Despite this vote, the number of childcare facilities increased, yet the coverage rate of childcare for children at preschool age remains low (18\%). However, French speaking cantons, but also urban regions have more support (FSIO, 2018). Furthermore, French speaking parents pay lower rates than their German speaking counterparts (EKFF, 2008). Despite the different fees, in both language regions professional childcare, combined with tax increases for dual earner couples, can erase a substantial part (or sometimes all) of a second income (Bütler, 2007), making it barely worthwhile to have a second income.

Previous research provides mixed results on reasons as to why parents in Switzerland opt for a gendered labor division. One view posits that the social policy, in particular the lack of childcare facilities, leads to mothers' reduction of working hours (Levy \& Widmer, 2013). The research suggests that parents embrace egalitarian values "the younger generation no longer reproduces traditional norms" (Krüger \& Levy, 2001, p. 154) and that they opt for gendered labor division despite their intent. Quantitative studies have found that the offer of childcare rather than its costs is positively related to the labor participation of mothers (Ernst Stähli, Le Goff, Levy, \& Widmer, 2009; Ravazzini, 2018; Stadelmann-Steffen, 2007). Moreover, research conducted in French speaking Switzerland reveals that parents commonly plan for more equal labor division before childbirth than they finally realize afterwards (Le Goff \& Girardin, 2016). Additionally, their views are more egalitarian than what is reflected in their allocation of paid and unpaid work (Tettamanti, 2016).

Research in the German speaking parts of Switzerland draws different conclusions: König (2012) argues that couples end up in gendered labor division by negotiating on a daily basis. Additionally, Stamm (2018) as well as Baumgarten et al. (2017) conclude that despite women's emancipation, ideals about motherhood have barely changed, leading mothers to prioritize their presence at home and to cut down their working hours. A study that combines social norms and policy found that both vary between language regions, and that both have an impact on parents' labor division (Epple, Gasser, Kersten, Nollert, \& Schief, 2014). Given these conditions, if we expect that the labor division is different between the language regions, the question remains as to how social policy and gendered culture interact.

\section{Methods and Data}

This research draws on data from two projects with intersectional foci: the AP (Maihofer, 2018) and the BP (Le Goff \& Levy, 2011). It is, in part, a secondary analysis. The combination of those data, both consisting of in-depth interviews about the transition to parenthood provides an opportunity to contrast women and men's experiences in two language regions. 
The AP study was designed to examine how 30-yearold women and men experience their current professional situation in gender typical, gender atypical and gender-neutral professions, as well as their ideas about how to reconcile family and professional life. It is a subsample of the longitudinal nationally representative study "transitions from education to employment" (TREE, 2016). 81 participants of the TREE-sample were contacted, and 47 agreed to be interviewed. The data were collected in 2014 and 2015 . The presented analysis focuses on women and men who wished to have or already had children. Participants from the AP sample who talked solely about their professional life and did not give information about the reconciliation of family and work (because the topic did not apply to their current situation) were excluded from the analysis. In the sample, 23 German speaking participants (11 women, 12 men) and 11 French speaking participants (six women, five men) remained. One woman self-identified as homosexual, whereas the other participants anticipated or lived parenthood as part of a heterosexual couple. Among the German speaking participants, three were expecting their first child and four had recently become parents for the first time when the interviews were conducted. Among the French speaking participants, two were expecting their first child and one was already a parent. The interviews were problem-centered (Witzel, 2000), meaning they were semi-structured and contained participants' objective conditions but also their subjective perception of a situation. The interview protocol included questions concerning the participants' professional trajectory, their career aspirations and the (anticipated) la- bor division as parents. Furthermore, they were asked to elaborate on gendered norms, and their perception of the institutional framework for parents.

The second data set consists of the qualitative sample of the longitudinal BP study. This study was conducted in the French speaking parts of Switzerland between 2005 and 2009 and its aim was to trace how parents' gendered labor division comes into existence. The participants first took part in a quantitative survey, by the end of which they were asked whether they agreed to give a more detailed interview. Participants self-registered for this study. A sample of 31 heterosexual couples were interviewed, men and women separately, once during the women's pregnancy and twice after the first transition to parenthood. Not all participants completed every wave: the first wave consisted of 62 interviews, the second (4-6 months after childbirth) of 38 interviews, and the third (12-24 months after first childbirth) of 44 interviews. As all participants anticipated parenthood no interviews were excluded. Similarly to the AP study, the interviews were semi-structured and the protocol included questions on participants' professional situation and their (anticipated) labor division as parents. Participants also described their objective situation as well as subjective perception of the situation.

In both datasets participants with a tertiary education were over-represented. Many were working in the service industries, in finance, administration, health, counselling, or teaching; only a few had jobs in the trade or agricultural sector (Table 1).

All interview transcriptions were coded using codes derived from the interview guidelines. The same coding

Table 1. Overview of the participants.

\begin{tabular}{|c|c|c|c|c|}
\hline \multirow{2}{*}{$\begin{array}{l}\text { Study } \\
\text { Anticipated Parenthood }\end{array}$} & \multicolumn{2}{|l|}{ French speaking } & \multicolumn{2}{|l|}{ German speaking } \\
\hline & Women & 6 & Women & 11 \\
\hline & Men & 5 & Men & 12 \\
\hline \multicolumn{5}{|l|}{ Participants were } \\
\hline interviewed once & Mean age/age range & $30 / 29-31$ & Mean age/age range & $30 / 29-31$ \\
\hline \multirow[t]{3}{*}{ 2014-2015 } & Education level: & & Education level: & \\
\hline & Tertiary & 10 & Tertiary & 14 \\
\hline & Secondary & 1 & Secondary & 9 \\
\hline Total & & 11 & & 23 \\
\hline \multirow[t]{2}{*}{ Becoming Parents } & Women & 31 & & \\
\hline & Men & 31 & & \\
\hline \multirow{3}{*}{$\begin{array}{l}31 \text { couples, } 3 \text { waves (before } \\
\text { and after the first transition } \\
\text { to parenthood) }\end{array}$} & & & & \\
\hline & Mean age/age range & $31 / 22-40$ & & \\
\hline & Education level: & & & \\
\hline \multirow[t]{3}{*}{ 2005-2009 } & Tertiary & 41 & & \\
\hline & Secondary & 20 & & \\
\hline & Compulsory education & 1 & & \\
\hline Total & & 62 & & \\
\hline
\end{tabular}


scheme was utilized for both datasets. Then, women and men's discourses in both language regions before and after the transition to parenthood were contrasted. The analysis focuses on how women and men decide what their labor division as parents should look like. It examines their priorities, particularly, what form of care is considered the most suitable for their child. In addition, structural constraints linked to policy are taken into account (i.e., access to formal childcare, workplace constraints). For the present article, the citations were translated from French or German to English. For each citation we indicate the participants' gender and distinguish three family situations: childless, (partner) pregnant when they are expecting, as well as mother or father for young parents. We further specify the participants' job and, as several participants had the same profession, we indicate the study (AP, BP) and number of the interview.

\section{Results}

\subsection{Work}

\subsubsection{German Speaking Participants}

German speaking men point out that when they become fathers, they anticipate being the breadwinner of the family: "One has to provide for...[the] children" (man, childless, bank clerk, AP15). However, they also wish to be present for their child. To this end, many of them considered it ideal if a father worked a high level of parttime $(80 \%)$ work to "spend one day with the children" (man, childless, tax inspector, AP2). Some men anticipate full-time work as fathers because they think that no parttime jobs in their field are available or that part-time work has a negative impact on their career prospects. Only one man anticipates sharing breadwinning and caregiving equally. It is linked to his profession as a musician; he does not have the possibility to work a full-time job. The others consider the mother as being mainly responsible for childcare and indicate that she could "work some percentages" (man, childless, bank clerk, AP15), or stay at home.

Women's anticipations for the labor division as parents are in line with those of men. Most of them want their partner to work $80 \%$. For themselves they all anticipate part-time work, mostly about $40 \%$, in some exceptions up to $60 \%$. Even though it is clear for women that they will substantially reduce their working hours once they become mothers, this does not mean that their job is not important to them. Often, they have invested many resources in their education and indicate that their professional life endows meaning and identity. They consider their work as "a big part of life" (women, childless, human resources assistant, AP28), say that they have a "great job" (woman, childless, veterinarian, AP26) and like going to work. Women are aware that a reduction of working hours reduces their career prospects, but they consider that as an inevitable consequence of their choice to have children:
Somebody is just going to have to draw back.... think it's nice to be able to present a certain career and sometimes maybe a setback will come. But I decide either way [having children or having a career], but not both. (Women, childless, accountant, AP24)

Overall, German speaking women anticipate that their professional life will lose its meaning as soon as they become mothers. Nonetheless, they wish to stay in the labor market in order to have a change from being at home, staying "with half a foot" (woman, pregnant, communications specialist, AP4) in professional life or to have a "little money of their own" (woman, childless, veterinarian, AP26). These results of parents' anticipated labor division are in line with previous research on the AP data (Baumgarten, Luterbach, \& Maihofer, 2017; Baumgarten, Wehner, Maihofer, \& Schwiter, 2016).

\subsubsection{French Speaking Participants}

In contrast to the German speaking participants, before having children, most French speaking men and women indicate that sharing earning and caring is the best solution for a couple. They reject the idea of a mother's responsibility to provide childcare and of a father's to be the breadwinner: "It is not the question that I earn enough money, but that I and my wife, both working, earn enough to sustain the family" (men, childless, engineer, AP4). Another participant considers a gendered labor division as an "outdated idea," which persists because "change needs time" (woman, childless, teacher, AP5).

Childless men typically indicate that circumstances, like the professional situation of each parent at a given moment will determine their labor division as parents. Many also stress the importance of being present for their child and consider a reduction of their working hours when being a father: "I could work 50\%...for me it's no problem to stay at home and take care of the children and clean" (man, childless, nurse, AP9). However, when interviewed during their partner's pregnancy, only a few fathers-to-be who indicate a desire to work part-time had asked their employers to reduce their working hours. Among the others, two options can be observed: Men from the first group mention that working part-time is an option, but they explain that it is too early to make a decision: "I don't know yet very well what it means to be a father, therefore I won't ask [for a reduction] now" (man, partner pregnant, engineer, BP367). They also indicate that they could still adapt their working hours if needed. The second group is composed of fathers-to-be that wish to work part-time but consider it impossible. They mention financial constraints or that their job cannot be done part-time. Most frequently they think that no part-time positions are available: "Positions that will open up are a priori only for $100 \%$ " (man, partner pregnant, teacher, BP362). Alternatively, they believe that their employer would not agree if they asked to reduce their working hours: "A reduction...is quite difficult....I don't think that 
this will be accepted" (man, partner pregnant, technical collaborator, BP11). Only one father-to-be says he wishes to work full-time, because he likes his job: "No I think professionally.... don't necessarily want to change" (man, partner pregnant, journalist, BP231).

Childless women also remain vague about what their labor division as parents could look like. However, most of them anticipate a reduction in working hours when they become mothers. By the time they are pregnant, they usually negotiate with their employer to obtain a part-time position. Most, but not all employers grant the reduction. For women in male dominated sectors (e.g., finance, engineering) it is more difficult to get a part-time position than in mixed or female dominated domains like teaching or care professions. If part-time work is in conflict with professional options, women prioritize parttime work. An engineer, for example, explains that she took the risk of not getting a job by telling a potential employer that "it's out of the question that I work 100\%" (mother, engineer, BP231). A bank clerk whose demand to reduce working hours was not accepted said: "As they did not accept my $50 \%$ for after [childbirth]...I quit" (women, pregnant, bank clerk, BP209).

In French speaking regions, mothers-to-be anticipate higher working hours than in the German speaking parts. Most plan to work between $50 \%$ and $80 \%$, but there is high variability: Expected working hours range between $20 \%$ and $100 \%$. The highest working hours are anticipated among mothers-to-be in the urbanized Lake Geneva region. In this region many women wish to continue working $80 \%$ or full-time: "I have always worked to finance my studies, for the baby I don't see any difference....I would like to work 100\%" (woman, pregnant, student/secretary, BP68). Many mothers-to-be are concerned about how to reconcile breastfeeding and employment. Some plan to extend the short maternity leave with an unpaid leave, while others remain ambivalent about resuming work "either I stop breastfeeding at that moment...[or] I work only a few hours" (women, pregnant, therapist, BP43).

Mothers-to-be usually intend to continue working after childbirth because they wish to "balance" (woman, pregnant, engineer, BP231) professional life and family life. Some also worry about the loss of career prospects: "Once the little one goes to school...there's still a whole life behind it and then it's maybe a pity to put such a drastic brake on a career" (woman, pregnant, information specialist, BP30). In these cases, mothers-to-be typically opt for an $80 \%$ position as a trade-off between having time to spend with the child and continuing their professional career. Though not all women were career oriented, in particular among the lower educated, some of them indicate that ideally they wished to stay at home, but went to work because they considered their income as essential: "I had stopped [working]...but financially this is not possible" (woman, pregnant, nurse assistant, BP336). Rarely, women also indicate that they continue working to avoid financial dependence on the partner.
In sum, during their pregnancy women take steps to be able to reduce their labor force participation after childbirth. Meanwhile, the majority of men at that time indicate that it is too early to decide about a reduction of working hours or that reducing working hours would be impossible due to financial and labor market constraints. However, only fathers-to-be state that no part-time position is available. If mothers-to-be do not get a part-time position they look for another job. Further, a comparison of men and women holding the same job reveals that while men considered that their job is unsuitable for part-time work, women declare that working part-time was unproblematic, or at least possible. A gender difference can also be observed in the discourse about financial constraints: Men sometimes say that they anticipate working full-time because they earn more. However, it is almost exclusively mothers-to-be who anticipate reducing their labor force participation, even if they outearn their partner.

\subsection{Childcare}

\subsubsection{German Speaking Participants}

Most German speaking participants prefer parental childcare: Typical statements are that children "come first" (woman, childless, psychologist, AP10) and that "parents should raise the children" (man, childless, bank clerk, AP15). Many also consider it pointless to start a family if the children are cared for by a nursery: "I don't want to take the kid to daycare...there's a reason for having a kid in the first place" (man, partner pregnant, business economist, AP5). While some participants avoid non-parental care because they consider it the parents' responsibility to take care of their children by themselves, others are concerned about the child's well-being and education. They worry that in daycare the child misses an attachment figure, that no one is there if he or she is not well or that a nursery weakens the bond between parents and children. One mother-to-be details her concerns: "I wouldn't want my kid to be raised by the state...well by other people." She worries about the influence of the childcare, educating the child according to different beliefs than her own: "I would like to pass on my family traditions....I would not like to get it dictated by someone 'no, you have to do it that way"' (woman, pregnant, escrow clerk, AP6).

This does not imply that German speaking participants are totally against non-parental care. Usually they prefer care provided by family members (mostly their own parents) for up to two days a week. A few participants also suggested that parents should help each other instead of relying on formal structures: "I would find it rather better if daycare would be self-organized [by parents] in the form of lunch tables" (women, childless, accountant, AP24). A minority of participants do not prefer informal childcare. A woman indicates that it "irritates" her that grandmothers commute to avoid a child going 
to daycare. She considers this as "conservative thinking" (women, childless, translator, AP12) and for her a child is as well cared for in daycare as by the grandmother. Very few other participants also consider daycare a good option, but argue that it is too costly.

The preference for parental care makes dual-earning unfeasible. Therefore, all German speakers anticipate that at least one parent substantially reduces labor force participation. Although most participants emphasize the necessity of a parent being present at home, for most it goes without saying that it must be the mother. For some participants this is due to nature: "When a child is born, the mother is more in demand, that's just a natural condition" (man, childless, tax inspector, AP2). Other participants indicate that it is up to each couple regarding which parent will stay at home, "it has to suit everyone individually" (man, childless, corporate client advisor, AP30), or that relative incomes determine the labor division. However, the majority of participants hardly imagine fathers as main caregivers and mothers as main earners. A young mother indicated that she had a decent salary before childbirth and could have sustained a family while she considered her partner's income as insufficient. She says: "I think I couldn't bring myself to just go to work and leave the child with the father," and adds "I am the mother, I stay at home....I would like to...have the mother role...and do the housework and take care of the child" (mother, teacher, AP27). This shows that presence at home is closely tied to motherhood, which is not the case for fatherhood. Participants usually consider a father's full-time work as unproblematic. When asked whether they think that full-time working fathers do not see their children enough, only one participant agreed, whereas the others emphasized that he makes "the most of the limited time" (man, partner pregnant, business economist, AP5) or that working less would conflict with the responsibility to sustain a family.

The few German speaking participants who are parents arrange their roles in gender differentiated ways: Fathers are breadwinners, some working part-time, while mothers work small part-time jobs or stay at home. As most of the time a parent is present at home, partners experience few time conflicts. However, the need to avoid a decrease in the standard of living, a lack of variety at home or a desire to continue an education are being expressed as reasons as to why mothers continue their professional activities. Nonetheless, for mothers, going back to work can evoke mixed feelings: A mother who has reuptaken her work one day per week asked herself whether it was "the right thing to do" or whether she was "selfish" (mother, teacher, AP27).

\subsubsection{French Speaking Participants}

French speaking participants have divergent opinions about the ideal care of their child. While some think that parents should take care of the child by themselves, others are open to non-parental care: "I have no worries that my baby is around 15 other children" (women, pregnant, engineer, BP231). Most participants lie between the two positions and believe that non-parental childcare for some days a week favors the child's development and its ability to interact with other children.

Many parents-to-be who want to rely on professional care cannot do so because "places in nurseries are scarce and expensive" (woman, pregnant, physician, BP12), as one participant summarized it. Nurseries have long waitlists, and outside urban areas there are often no facilities at all. Some participants bemoan this lack of access to professional childcare and consider it necessary that public financing is increased. In cases when they do not obtain a place in a nursery, parents turn towards nonprofessional, so called 'family day care' in which another person, usually a mother, serves as a 'day mother' to the child. Family day care provides enough places, and it is significantly less costly than professional care. For smaller amounts of care, many participants also rely on their own parents. These informal care solutions make dual-earning possible.

Some parents-to-be prefer parental care. In this case, men typically want their wife to reduce her working hours, whereas women usually anticipate a more equal share of paid and unpaid work. In most cases, though, mothers are not able to put their intention into practice, as their husbands do not contribute the expected proportion of housework and childcare. Therefore, mothers, who are considered responsible for caregiving, readapt. One way to do so is for the mother to interrupt her career against her initial intentions. In that case, mothers consider the reduction of working hours as temporary, which leaves them "kind of a lifeline helping...to get over this sacrifice" (mother, secretary/student, BP68). Yet, the adaption is sometimes difficult: "It's hard, it's a grief all the same" (mother, midwife, BP351). Other women reconsider their priorities concerning childcare: "When I was pregnant, I had said never the nursery...finally I agreed to visit the nursery but I said he won't go there anyway, and finally I liked the nursery very much" (mother, teacher, BP180).

Despite mothers adapting their view on childcare, among those who work $80 \%$ or more, feelings of guilt were ubiquitous. A mother who is the breadwinner of her family says roughly one year after childbirth: "I am torn...on one side I still feel guilty, I have not yet fixed this...on the other side I want to work" (mother, accountant, BP4). Further, working mothers often suffer from time conflicts. They bemoan the incompatibility of their work schedule with the necessity to pick up the child from childcare or to be at home to breastfeed on time. Often, they are exhausted, which sometimes leads them to question their arrangement: "If I have a second child I will stop [working]" (mother, midwife, BP351).

Even though many fathers work more than they wished to, they refer in positive terms to their workfamily reconciliation. They point out the time they spend at home besides their full-time work, and part-timers are 
often proud of their investment for the family: "Having this $80 \%$ [job] really shows... [that] I'm...making...a lot of effort or sacrifice to have a life...as a dad....I really feel that I'm present" (father, risk manager, BP16). Some fathers do not insist on their presence, but on the fact that both parents are able to continue their careers: "[S]he's [the wife] taken up her work, I've taken up mine....I think it's great" (father, journalist, BP231). In contrast, his wife refers in more negative terms to their arrangement. She says that at times she was so exhausted that she "couldn't go on anymore" (mother, engineer, BP231).

This does not mean that fathers are sheltered from work-family conflicts: The more they share caregiving, the more they feel stressed and tired as well. However, if the situation becomes too stressful, fathers also rely on other persons, mostly their wife or their mother, to take care of the child: "I have repeatedly expressed my displeasure and my frustration to my wife...and finally she...reduced [her working hours] to 20[\%]" (father, teacher, BP43).

\section{Conclusion}

The study is a within-country comparison, which analyzes how gendered culture and welfare policies shape how women and men anticipate and experience the transition to parenthood in the French and German speaking parts of Switzerland. Values about labor division are different in the two language regions: Before becoming parents, most French speaking women and men consider it ideal to share paid and unpaid work equally as parents, whereas their German speaking counterparts prioritize fathers' breadwinning and mothers' caregiving. However, in both language regions, parents opt for a gendered labor division. In German speaking parts, parents' sharing of paid and unpaid work is largely congruent with the expressed values, whereas French speaking couples become more inegalitarian than they anticipated. The inequality comes into the picture during pregnancy when fathers' paid work is given priority, and mothers opt for a part-time position to reconcile caregiving and employment. After childbirth, the differentiated roles are reinforced.

This comparison provides some insights into the interaction of policy and gendered culture. Switzerland is characterized by little government support for families and a relatively unregulated labor market. Our results reveal that the labor market structure is an important driver for the observed gendered labor division. Women and men in both language regions are aware that working part-time implies a reduction of career prospects. For fathers, this labor market structure is congruent with the male breadwinner norm and contributes to high working hours. Due to this, most fathers were less involved in care work than they had originally anticipated. Nonetheless, they focus on the time they spend with their children besides work and usually refer in positive terms to the couples' labor division.
Mothers' insertion in the labor market varies between language regions. German speakers consider childcare to be the responsibility of the parents, and most of them avoid formal care, even to a smaller extent. In this context of matching policy and personal responsibility for childcare, women, usually denominated as the caregiver, find it hard to imagine themselves as mothers having high working hours. Furthermore, among mothers, even small part-time work can lead to worries about the child's well-being and feelings of guilt.

French speakers are generally more open to state support for families and therefore more open to nonparental and formal childcare as German speakers. There are also more childcare facilities available in the French language regions and, as it turns out, even some parents who were originally skeptical towards formal childcare also take advantage of this option, as it allows them to continue their professional activities. But despite the overall larger offer of childcare facilities in the French speaking regions, the supply cannot match the demand. An informal childcare market therefore fills the gap in availability. All in all, for French speaking mothers, the individual situation shapes their insertion in the labor market: Those who worry about their career, often opt for an $80 \%$-position as a trade-off between professional opportunities and care demands. Others decide to reduce more or interrupt labor force participation to avoid the double load of job and childcare, to be able to breastfeed beyond the brief maternity leave, or because they prefer parental care. The higher acceptance of working mothers is also shown by the observation that the only ones who express feelings of guilt are those who work high percentages. Also, French speaking women who reduced their working hours against their initial intentions consider this as a sacrifice. Such a discourse can not be observed among German speaking mothers, who think (at least during the transition to parenthood) that, as a mother, their professional life has to come second.

Furthermore, both culture and policy reduce the individual leeway. This analysis shows that if there is a congruence between policy and gendered culture, participants discourses and behaviors are more homogeneous (fathers and German speaking mothers) than if there is a disparity between the two (French speaking mothers). French speaking mothers whose work is mostly accepted, but is not supported by welfare policy, face more time conflicts and ambivalences than German speaking mothers, but there is a broader variety of conceivable options for them. These results are in line with research that shows that women have more time conflicts than men (Notten, Grunow, \& Verbakel, 2017), and that in Switzerland, mothers' working hours are positively correlated with an increase in time conflict (Stadelmann-Steffen \& Oehrli, 2017).

The research shows that substantial variations between gendered culture and policy that shape parents' labor division can exist not only among, but also within countries. However, we must keep in mind that these 
results are based on two different datasets. Among French speakers, we observe a more egalitarian discourse, despite the data on becoming parents being almost a decade older than the anticipated parenthood data. Nonetheless, in Switzerland a small change towards equality has occurred between the two studies (FSO, 2019). Therefore, we cannot omit that the results underrepresent the differences between the language regions. Moreover, the sample size is small, in particular among German speakers, which might reduce the variety in observation. In addition, the study only focuses on the transition to parenthood. More research, also with longitudinal data, needs to be conducted to cover a longer period than the transition to parenthood. Further, the presented analysis is limited to individuals who are mostly affluent enough that dual-earning is an option rather than an obligation. Future research should continue to investigate how gendered culture in the transition to parenthood is experienced by other groups of society.

\section{Acknowledgments}

Data collection for this publication has been supported by the National Centre of Competence in Research LIVES-Overcoming Vulnerability from a Life-Course Perspective (NCCR LIVES), funded by the Swiss National Science Foundation (grant number: 51NF40-160590).

\section{Conflict of Interests}

The authors declare no conflict of interests.

\section{References}

Armingeon, K., Bertozzi, F., \& Bonoli, G. (2004). Swiss worlds of welfare. West European Politics, 27(1), 20-44.

Ballestri, Y., \& Bonoli, G. (2003). L'Etat social suisse face aux nouveaux risques sociaux [The Swiss welfare state in face of new social risks]. Swiss Political Science Review, 9(3), 35-58.

Baumgarten, D., Burri, J., \& Maihofer, A. (2017). Die Entstehung der Vorstellungen von Familie in der (deutschsprachigen) Schweiz [The emergence of the concept of family in (German-speaking) Switzerland]. Basel: University of Basel.

Baumgarten, D., Luterbach, M., \& Maihofer, A. (2017). Wenn Kinder da sind, kommen die an erster Stelle. Sonst muss man keine Familie haben [If we have children, they come first. Otherwise, there is no need to have a family]. Freiburger Zeitschrift für Geschlechterstudien, 23(1), 1-17.

Baumgarten, D., Wehner, N., Maihofer, A., \& Schwiter, K. (2016). Wenn Vater, dann will ich Teilzeit arbeiten: Die Verknüpfung von Berufs- und Familienvorstellungen bei 30-jährigen Männern aus der deutschsprachigen Schweiz [As a father, I want to work parttime: How 30-year-old men from German-speaking
Switzerland link concepts of career and family]. Kultur, Gesellschaft Sonderheft, 4, 76-91.

Bertolini, S., Musumeci, R., Naldini, M., \& Torrioni, P. M. (2019). The transition to parenthood in Italy: Reasons for non-normativity. In D. Grunow \& M. Evertsson (Eds.), New parents in Europe: Work-care practices, gender norms and family policies (pp. 148-168). Cheltenham: Edward Elgar Publishing.

Bielby, D. D. (1992). Commitment to work and family. Annual Review of Sociology, 18(1), 281-302.

Bühler, E. (2002). Formen der Vereinbarkeit von Erwerbstätigkeit und Familie [Ways of reconciling work and family life]. Geographische Zeitschrift, 90(3/4), 167-179.

Bühlmann, F., Elcheroth, G., \& Tettamanti, M. (2010). The division of labour among European couples: The effects of life course and welfare policy on valuepractice configurations. European Sociological Review, 26(1), 49-66.

Bütler, M. (2007). Arbeiten lohnt sich nicht: Ein zweites Kind noch weniger. Zum Einfluss einkommensabhängiger Tarife in der Kinderbetreuung [Working is not worth it: Having a second child even less. About the influence of income-based childcare rates]. Perspektiven der Wirtschaftspolitik, 8(1), 1-19.

Carmichael, F., \& Ercolani, M. G. (2016). Unpaid caregiving and paid work over life-courses: Different pathways, diverging outcomes. Social Science \& Medicine, 156, 1-11.

EKFF. (2008). Familien- und schulergänzende Kinderbetreuung [Family- and school-complementary childcare]. Bern: EKFF. Retrieved from https:// www.ekff.admin.ch/fileadmin/user_upload/ekff/ 05dokumentation/d_09_Publ_Kinderbetreuung.pdf

Epple, R., Gasser, M., Kersten, S., Nollert, M., \& Schief, S. (2014). Parenthood and employment: The impact of policies and culture on gender inequality in Switzerland. Equality, Diversity and Inclusion: An International Journal, 34(2), 141-154.

Ernst Stähli, M., Le Goff, J.-M., Levy, R., \& Widmer, E. (2009). Wishes or constraints? Mothers' labour force participation and its motivation in Switzerland. European Sociological Review, 25(3), 333-348.

FCh. (2004). Änderung vom 03.10.2003 des Bundesgesetzes über die Erwerbsersatzordnung [Adjustment of the federal law on the compensation of income from 03.10.2003]. FCh. Retrieved from https://www. bk.admin.ch/ch/d/pore/va/20040926/can513.html

FCh. (2013). Bundesbeschluss vom 15.06.2012 über die Familienpolitik [Federal decree on family policy from 15.06.2012]. FCh. Retrieved from https://www.bk. admin.ch/ch/d/pore/va/20130303/can567.html

FSIO. (2018). Evaluation "Anstossfinanzierung." Entspricht das bestehende Angebot an familienergänzender Kinderbetreuung der Nachfrage? Forschungsbericht 14/17 [Evaluation "start-up financing". Does the existing offer of complementary childcare meet the demand? Research Report 14/17]. 
Bern: FSIO. Retrieved from https://www.bsv.admin. ch/dam/bsv/de/dokumente/familie/studien/ Evaluation_Angebot_Nachfrage_2017.pdf.download. pdf/14_17d_eBericht.pdf

FSO. (2013). Das Engagement der Väter in Haushalt und Familie [The commitment of fathers in the household and the family]. FSO. Retrieved from https://www. bfs.admin.ch/bfsstatic/dam/assets/348982/master

FSO. (2016). Mütter auf dem Arbeitsmarkt [Mothers in the labor market]. FSO. Retrieved from https://www.bfs.admin.ch/bfsstatic/dam/assets/ 1061095/master

FSO. (2019). Gleichstellung von Frau und Mann im europäischen Vergleich [Equality of women and men in a European comparison]. FSO. Retrieved from https://www.bfs.admin.ch/bfs/de/home/statistiken/ wirtschaftliche-soziale-situation-bevoelkerung/ gleichstellung-frau-mann.assetdetail.11068535.html

Gangl, M., \& Ziefle, A. (2015). The making of a good woman: Extended parental leave entitlements and mothers' work commitment in Germany. American Journal of Sociology, 121(2), 511-563.

Gatrell, C. (2005). Hard labour: The sociology of parenthood. Maidenhead: McGraw-Hill Education.

Geser, H. (2003). Sprachräume als Arbeits- und Organisationskulturen: vergleichende empirische Befunde in der deutschen und französischen Schweiz [Language regions as work and organizational cultures: comparative empirical findings in German and Frenchspeaking Switzerland]. Zurich: University of Zurich.

Grunow, D. (2019). Comparative analyses of housework and its relation to paid work: Institutional contexts and individual agency. KZfSS Kölner Zeitschrift für Soziologie und Sozialpsychologie, 71(1), 247-284.

Grunow, D., \& Evertsson, M. (2016). Couples' transitions to parenthood: Analysing gender and work in Europe. Cheltenham: Edward Elgar Publishing.

Grunow, D., \& Evertsson, M. (2019). New parents in Europe: Work-care practices, gender norms and family policies. Cheltenham: Edward Elgar Publishing.

Hays, S. (1996). The cultural contradictions of motherhood. New Haven, CT: Yale University Press.

Johansson, T., \& Andreasson, J. (2017). Fatherhood in transition. London: Palgrave Macmillan.

Johnston, D. D., \& Swanson, D. H. (2006). Constructing the "good mother": The experience of mothering ideologies by work status. Sex Roles, 54(7/8), 509-519.

König, T. (2012). Familie heißt Arbeit teilen [Being a family means sharing work]. Konstanz: UVK.

Krüger, H., \& Levy, R. (2001). Linking life courses, work, and the family: Theorizing a not so visible nexus between women and men. Canadian Journal of Sociology, 26(2), 145-166.

Kühhirt, M. (2011). Childbirth and the long-term division of labour within couples: How do substitution, bargaining power, and norms affect parents' time allocation in West Germany? European Sociological Review, 28(5), 1-18.
Le Goff, J.-M., \& Girardin, N. (2016). Répartition des tâches domestiques et de soins aux enfants: Intentions et pratiques [Allocation of household and child care tasks: Intentions and practices]. In J.-M. Le Goff \& R. Levy (Eds.), Devenir parents, devenir inégaux [Becoming parents, becoming unequal] (pp. 76-108). Zurich: Seismo.

Le Goff, J.-M., \& Levy, R. (2011). Devenir parent: Rapport de recherche [Becoming a parent: Research report]. Lausanne: University of Lausanne. Retrieved from www.lives-nccr.ch/sites/default/files/pdf/ publication/8_lives_wp_legoff_devenirparent.pdf

Lee, M. (2015). Legislative initiative for work-family reconciliation in South Korea: A comparative analysis of the South Korean, American, French, and German family leave policies. Asian American Law Journal, 22, 45-103.

Levy, R., \& Widmer, E. (2013). Gendered life courses between standardization and individualization: A European approach applied to Switzerland. Munster: LIT Verlag.

Maihofer, A. (2018). Wie beeinflussen Vorstellungen von Familie und Beruf die Berufsverläufe von jungen Männern* und Frauen*? [How do ideas about family and profession influence the career paths of young men and women?]. Basel: University of Basel.

McGill, B. S. (2014). Navigating new norms of involved fatherhood: Employment, fathering attitudes, and father involvement. Journal of Family Issues, 35(8), 1089-1106.

Miller, T. (2005). Making sense of motherhood: A narrative approach. Cambridge: Cambridge University Press.

Miller, T. (2011). Falling back into gender? Men's narratives and practices around first-time fatherhood. Sociology, 45(6). https://doi.org/10.1177/ 0038038511419180

Misra, J., Budig, M., \& Boeckmann, I. (2011). Workfamily policies and the effects of children on women's employment hours and wages. Community, Work \& Family, 14(2), 139-157.

Notten, N., Grunow, D., \& Verbakel, E. (2017). Social policies and families in stress: Gender and educational differences in work-family conflict from a European perspective. Social Indicators Research, 132(3), 1281-1305.

O'Brien, M. (2009). Fathers, parental leave policies, and infant quality of life: International perspectives and policy impact. The Annals of the American Academy of Political and Social Science, 624(1), 190-213.

Pettit, B., \& Hook, J. (2005). The structure of women's employment in comparative perspective. Social Forces, 84(2), 779-801.

Pfau-Effinger, B. (2005). Culture and welfare state policies: Reflections on a complex interrelation. Journal of Social Policy, 34(1), 3-20.

Pfau-Effinger, B. (2012). Women's employment in the institutional and cultural context. International Journal of Sociology and Social Policy, 32(9), 530-543. 
Ravazzini, L. (2018). Childcare and maternal part-time employment: A natural experiment using Swiss cantons. Swiss Journal of Economics and Statistics, 154(15). https://doi.org/10.1186/s41937-017-0003-x

Rönkä, A., Oravala, S., \& Pulkkinen, L. (2003). Turning points in adults' lives: The effects of gender and the amount of choice. Journal of Adult Development, 10(3), 203-215.

Saraceno, C., \& Keck, W. (2011). Towards an integrated approach for the analysis of gender equity in policies supporting paid work and care responsibilities. Demographic Research, 25(11), 371-406.

Schober, P. S. (2011). The parenthood effect on gender inequality: Explaining the change in paid and domestic work when British couples become parents. European Sociological Review, 29(1), 74-85.

Stadelmann-Steffen, I. (2007). Der Einfluss der sozialpolitischen Kontexte auf die Frauenerwerbstätigkeit in der Schweiz [The influence of socio-political contexts on the employment of women in Switzerland]. KZfSS Kölner Zeitschrift für Soziologie und Sozialpsychologie, 59(4), 589-614.

Stadelmann-Steffen, I., \& Oehrli, D. (2017). Perceiving reconciliation: Child care policies and gendered time conflicts. Gender \& Society, 31(5), 597-623.

Stamm, M. (2018). Neue Väter brauchen neue Mütter: warum Familie nur gemeinsam gelingt [New fathers need new mothers: Why a family can only succeed together]. Munich: Piper Verlag.

Strub, S. (2003). Teilzeitarbeit in der Schweiz [Parttime work in Switzerland]. Bern: Büro BASS. Retrieved from http://www.buerobass.ch/pdf/2003/ teilzeitarbeit_schlussbericht.pdf

Tettamanti, M. (2016). Devenir parent en Suisse: Une situation paradoxale? [Becoming a parent in Switzerland: A contradictory situation?]. In J.-M. Le Goff \& R. Levy (Eds.), Devenir parents, devenir inégaux [Becoming parents, becoming unequal] (pp. 109-129). Zurich: Seismo.

TREE. (2016). Daten [Data]. TREE. Retrieved from https:// www.tree.unibe.ch/daten/index_ger.html

Vitali, A., \& Mendola, D. (2014). Women as main earners in Europe (Working Paper 56). Southampton: ESRC Centre for Population Change.

Witzel, A. (2000). The problem-centered interview. Forum: Qualitative Social Research, 1(1). Retrieved from http://nbn-resolving.de/urn:nbn:de:0114fqs0001228

\section{About the Authors}

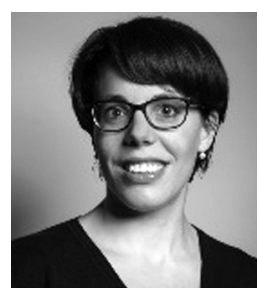

Regula Zimmermann is a Social Scientist at the University of Basel (Switzerland). Her research focuses on the structuring of life courses and gender inequalities. She is currently working on the longitudinal study 'Becoming Parents,' which traces the career and family paths of young mothers and fathers.

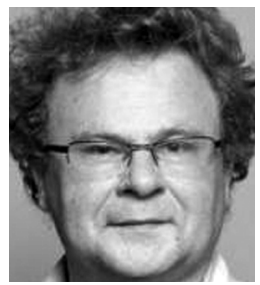

Jean-Marie Le Goff is a Senior Researcher and Lecturer at the Social Sciences Institute of the University of Lausanne (Switzerland) and an Associate Researcher at the Swiss National Center of Competence in Research-Overcoming Vulnerability: Life Course Perspectives (LIVES). His research interests include the transition to parenthood, family life, and more broadly life course studies. 